University of New Haven

University of

New Haven

Digital Commons@ New Haven

$8-7-2012$

\title{
Accountability and Evidence-Based Approaches: Theory and Research for Juvenile Justice
}

David Myers

University of New Haven, dmyers@newhaven.edu

Follow this and additional works at: http://digitalcommons.newhaven.edu/criminaljustice-facpubs Part of the Criminology and Criminal Justice Commons

\section{Publisher Citation}

Myers, D. L. (2013). Accountability and evidence-based approaches: Theory and research for juvenile justice. Criminal Justice Studies, 26(2), 197-212.

\section{Comments}

This is an Accepted Manuscript of an article published by Taylor \& Francis in Criminal Justice Studies on 07 Aug 2012, available online: http://www.tandfonline.com/doi/abs/10.1080/1478601X.2012.709853. 
Running Head: ACCOUNTABILITY \& EVIDENCE-BASED APPROACHES

Accountability and Evidence-Based Approaches:

Theory and Research for Juvenile Justice

\author{
David L. Myers \\ Indiana University of Pennsylvania
}

Correspondence should be addressed to Dr. David L. Myers, Department of Criminology, Indiana University of Pennsylvania, Indiana, PA 15705. Electronic mail may be sent to david.myers@iup.edu. 


\begin{abstract}
As part of the "accountability movement" in juvenile justice, policymakers, funding agencies, and the general public have called for greater accountability from agencies and organizations involved with youthful offenders. Within this context, performance measurement and monitoring, and use of evidence-based programs and practices, have emerged as recommended aspects of juvenile justice system operations nationwide. Little is known empirically, however, about the actual performance of juvenile justice systems or the real changes brought by contemporary reforms, and theory and research on the implementation and sustainability of evidence-based approaches have been slow to emerge. This paper will review the key aspects of the modern accountability movement in juvenile justice, and then discuss a recently proposed theory that may be useful in future examinations of juvenile justice system improvement efforts. A suggested research agenda also is presented.
\end{abstract}

Keywords: Accountability, performance measurement, evidence-based programs and practices 
Accountability and Evidence-Based Approaches:

Theory and Research for Juvenile Justice

In modern times, calls for greater accountability and use of evidence-based policies, programs, and practices have been heard across many disciplines (see, e.g., Aarons \& Sawitzky, 2006; Davies \& Nutley, 2008; Hunter, Paddock, Ebener, Burkhart, \& Chinman, 2009; Moynihan \& Pandey, 2010; Nelson, Leffler, \& Hansen, 2009; Tseng, 2010). Poor economic conditions and large budget deficits have further increased the need for virtually all public institutions to produce meaningful information about the work they do, the effectiveness of their programs and services, and their organizational plans for the future. In the field of juvenile justice, policymakers, funding agencies, and the general public have been demanding greater accountability from juvenile courts and the agencies and organizations that serve children, youth, and their families (Bazemore, 2006; Harp, Bell, Bazemore, \& Thomas, 2006; Mears \& Butts, 2008; Thomas, 2006, 2008). In addition, evidence-based programs and practices have been touted as a way to improve the delivery and impact of juvenile justice interventions (Lipsey, Howell, Kelly, Chapman, \& Carver, 2010; Sherman, Farrington, Welsh, \& MacKenzie, 2002). Juvenile courts and human service agencies have been feeling the effects of these trends, and many struggle to produce solid evidence about their performance and offender outcomes, often due to poor planning and/or poor implementation and evaluation of their programs and services (Mears, 2010; Mears \& Butts, 2008; Welsh \& Harris, 2008).

The purpose of this paper is to examine contemporary efforts to enhance the accountability of juvenile justice agencies and organizations and the effectiveness of the programs and services they provide. A recently proposed theory will be discussed that may be useful in guiding future research on juvenile justice system improvement and assisting 
practitioners with adopting and sustaining evidence-based innovations. The theory by

Wandersman and his colleagues (2008) has not been applied or tested in the fields of juvenile and criminal justice, but prior research in other disciplines (e.g., mental health, substance abuse prevention) suggests that it holds great promise for better understanding the implementation of justice system improvement efforts and guiding both researchers and practitioners who are working in this area. A suggested research agenda also is presented, to encourage further theoretical testing and advance juvenile justice system operations in the $21^{\text {st }}$ century.

The Evolution of Juvenile Justice

Early juvenile courts were created to serve the "best interests" of children, emphasizing an informal and protective environment and resting on a philosophy of rehabilitation and individualized justice (Howell, 1997, 2003; Krisberg, 2005; Zimring, 2005). Over the course of the $20^{\text {th }}$ century, as juvenile courts spread rapidly across the nation, states and local jurisdictions developed their own specific rules, procedures, programs, and sanctions that collectively comprise juvenile justice in America (Mears \& Butts, 2008). Since the 1960s, in response to periods of rising crime rates and greater scrutiny of juvenile courts, the field of juvenile justice has experienced various stages of criticism and reform. By the end of the century, nationwide concern about serious and violent youthful offending combined with an overall "get tough" philosophy to produce a juvenile justice system that was more formal, adversarial, and punishment oriented. As virtually all states modified their juvenile codes, offender accountability and public safety come to the forefront as key system goals (Snyder \& Sickmund, 1995, 1999; Torbet et al., 1996; Torbet \& Szymanski, 1998).

Despite this contemporary move toward a more "criminalized" juvenile justice system, most states and juvenile courts have maintained language in their laws, policies, and procedures 
that preserves a traditional rehabilitative mission (Lipsey et al., 2010). Moreover, there is substantial evidence that the public supports a rehabilitative approach to dealing with juvenile offenders (Cullen, 2006), and many modern juvenile justice policies, programs, and practices do not fit neatly into the category of being punishment-oriented (Mears, Shollenberger, Willison, Owens, \& Butts, 2010). Rather, there has been a trend toward balancing punishment and rehabilitation, as seen in $21^{\text {st }}$ century restorative justice programs, graduated sanctions, and specialized courts, as well as through the use of risk and needs assessment and individualized treatment (Howell, 2003; Krisberg, 2005; Mears et al., 2010; Zimring, 2005). Many of these strategies and efforts have not been subjected to scientifically rigorous evaluation, however, and some other popular prevention and intervention methods have been found to be ineffective in changing behavior (Lipsey, et al., 2010; Mears, 2010; Mears et al., 2010; Sherman et al., 2002). Modern concerns about juvenile justice system effectiveness have combined with weak economic conditions and corresponding budget cuts to produce a current environment where greater accountability is expected not only from youthful offenders, but also from the juvenile justice agencies and organizations that process, treat, and sanction them (Bazemore, 2006; Harp et al., 2006; Mears \& Butts, 2008; Thomas, 2006, 2008). This has been particularly evident in calls for greater use of performance measurement and monitoring in juvenile justice. At the same time, evidence-based programs and practices have been recommended as a key aspect of juvenile justice system reform in the coming years (Lipsey et al., 2010; Sherman et al., 2002). As discussed below, however, both of these suggested areas for improvement have been met with varying degrees of skepticism and resistance, and common implementation challenges and barriers exist. 


\section{Measuring and Monitoring Performance}

In recent years, a number of authors have promoted the use of performance measurement and monitoring in juvenile justice as a way to increase accountability in systems operations, improve implementation efforts, and assess outcomes expected from policies, programs, and practices (Bazemore, 2006; Harp, Bell, Bazemore, \& Thomas, 2006; Mears \& Butts, 2008; Thomas, 2006, 2008). Although definitions of performance measurement vary, most descriptions emphasize the use of mission-based outcome measures that can be used to assess an organization's ability to provide anticipated programs and services and achieve the expected results. As stated by Harp et al., (2006):

Performance measurement is a process that is used to assess accomplishment of organizational strategic goals and objectives that support an agency's mission. It is a management tool for enhancing decision-making and accountability. Measuring performance is how agencies determine whether they are providing quality products at reasonable costs. Performance measures help policy makers and managers to assess mission-driven outcomes in relation to mission-driven expectations. In short, performance measures tell organizations how well they are doing. (p. 3)

In evaluation research terms, performance measurement is somewhat similar to conducting process evaluations and impact assessments (Mears \& Butts, 2008). The use of performance measurement for monitoring purposes, however, is built into an agency's ongoing operations; is used for management activities and decision-making; and typically does not attempt to utilize scientifically rigorous research designs that are able to establish cause and effect relationships. When done well, performance monitoring can show that an agency or organization is operating and providing programs as intended, and that desired changes or reforms are being implemented 
as expected. It can help identify problems as they arise and allow for corrective actions to be taken, and it can be used to determine if policies or programs under consideration are even likely to be effective. Finally, it can be used to assess whether specified goals, objectives, and outcomes are being achieved, and facilitate more scientifically rigorous process evaluations and impact assessments.

Using performance measurement for planning and monitoring policy and program implementation can be a particularly useful function, as most strategies and services are likely to be ineffective if they are poorly planned and implemented (Rossi, Lipsey, \& Freeman, 2004; Welsh \& Harris, 2008). Furthermore, utilizing performance measurement in combination with sound strategic planning allows for agency and program goals and objectives to be both specified and assessed. Subsequently, results can be used to improve agency operations, evaluate staff, inform stakeholders, and enhance the sustainability of the organization. In sum, performance monitoring has the potential to produce critical information for improving the operations, efficiency, and effectiveness of juvenile justice agencies and organizations (Bazemore, 2006; Harp et al., 2006; Mears \& Butts, 2008; Thomas, 2006, 2008).

Despite the promise and potential benefits of performance monitoring, "juvenile justice systems tend not to measure performance" (Thomas, 2006, p. 2). Rather, juvenile justice agencies and organizations typically produce case-processing data that describes work being done, but in a backward-looking manner that reveals little about the quality of program implementation and the effectiveness of services being provided. Indeed, "one of the most difficult aspects of performance measurement and monitoring is the selection of relevant criteria of evaluation" (Mears \& Butts, 2008, p. 268). A general goal is to identify and select measures 
that are most relevant to assessing the actual performance of juvenile justice agencies and organizations, but this goal has proven difficult to achieve.

Recent efforts to enhance and expand the use of performance measurement in juvenile justice share some common themes. First, it is consistently recommended that performance measures be value-driven and be strongly linked to the vision and mission of the juvenile justice agency or organization (Bazemore, 2006; Harp et al., 2006; Mears \& Butts, 2008; Thomas, 2006, 2008). This places performance measurement squarely in the realm of strategic planning, which has been receiving greater emphasis throughout the criminal justice system during the past decade (Carter, Gibel, Giguere, \& Stroker, 2007; Flaherty-Zonis, 2007; Stroker, 2010; Welsh \& Harris, 2008). Based on established values, vision, and mission, more specific agency and program goals and objectives can be articulated. Performance measures, then, should be directly linked to high priority goals, with corresponding objectives that clearly show anticipated measureable outcomes, along with a specified timeframe and criteria for success.

Within this context, recent efforts have focused on placing juvenile justice performance measures within a "balanced and restorative justice mission," which includes the three goals of offender accountability, youth competency development, and community protection (Bazemore, 2006; Harp et al., 2006; Thomas, 2006, 2008). Within this recommended framework, juvenile justice agencies and organizations are responsible for specifying measurable objectives to be used in assessing whether the three overall goals are being met. Agencies and organizations also are responsible for implementing an efficient data collection and analysis plan and system, which will allow for reliable and valid data to be collected and appropriate performance measures to be produced. Resulting performance information then can be used to produce outcome reports, 
inform stakeholders, evaluate staff, improve agency operations, support budget and external funding requests, and reinforce performance-based management.

Mears and Butts (2008) have concluded that, "given the growing demands for accountability, the substantial costs of juvenile justice, the potential for harm to victims and communities, and, not least, the risk of failing to improve the life outcomes of young offenders, systematic implementation of performance monitoring in juvenile justice is essential” (p. 280). Despite support in the literature for this assertion, practitioners generally greet the subject of performance measurement with skepticism and resistance (Harp et al., 2006), and various funding, technological, and political barriers exist (Mears \& Butts, 2008). In addition, empirical studies on the use of performance measurement in juvenile justice are limited. Research to date greatly consists of descriptive case studies from the first two states (Pennsylvania and South Carolina) that implemented statewide juvenile justice performance measurement strategies, with Allegheny County, Pennsylvania, being the focus of much of this description (Thomas, 2006, 2008). Deschutes County, Oregon, and Marquette County, Michigan, also have participated in documented demonstration projects, while at least 20 other jurisdictions representing several states have established their own performance measurement initiatives (Thomas, 2005).

\section{Evidence-Based Programs and Practices}

At the same time that performance assessment has been advanced as a way to increase accountability and effectiveness in juvenile justice, evidence-based programs and practices also have been touted as a way to improve the delivery and impact of juvenile justice interventions and services. As recently summarized by Lipsey and colleagues (2010), the evidence-based approach seeks to provide: 
...the integration of a forward-looking administrative model with evidence-based programming. The administrative model is organized around risk management and risk reduction aimed at protecting the public by minimizing recidivism. Evidence-based programming is organized around services that moderate criminogenic risk factors and enhance adaptive functioning for the treated offenders. ... Such a system is consistently forward-looking in basing program placements and supervision levels upon objective risk and needs assessments and in constructing case management plans focused on improving future behavior rather than punishing past behavior. (p. 5)

Through evidence-based juvenile justice programs and practices, prevention and intervention programs that are supported by scientifically rigorous evaluations are to be matched with appropriate at-risk youths and offenders. In recent decades, as more prevention and intervention programs have been evaluated through randomized controlled trials and scientifically rigorous quasi-experimental studies, a body of evidence has accumulated that allows for the identification of "effective" programs (Emshoff, 2008; Kyler et al., 2005; Lipsey et al., 2010; Sherman et al., 2002). Lipsey et al. (2010) further discuss three specific approaches for distinguishing evidencebased programs. First, there can be direct evaluation of the effects of a program as implemented, which produces results that apply in a very specific manner to the particular program as practiced. Second, model programs exist that are based on documented evidence of effectiveness, which has been certified by a credible source. Examples include the University of Colorado's "Blueprints for Violence Prevention" and the Office of Juvenile Justice and Delinquency Prevention's “Model Programs Guide.” Third, best practice guidelines can be produced that are based on meta-analysis of larger numbers of research findings. This approach 
allows practitioners and policymakers to determine which program types are supported by credible evidence.

In addition to utilizing programs that have been supported through scientifically rigorous evaluation research, evidence-based practice also includes the use of risk and needs assessment; targeting higher risk (rather than lower risk) cases for appropriate treatment; focusing on constructive personal development and positive reinforcement, rather than control and deterrence; and implementing, monitoring, and evaluating programs, to ensure they are delivered as intended and the expected results are being achieved (Kyler et al., 2005; Lipsey et al., 2010; Mears, 2010; Mears \& Butts, 2008; Mears et al., 2008; Sherman et al., 2002). Along with the field of juvenile justice, during the past 10 years evidence-based programs and practices have been advocated and implemented throughout the field of corrections (Christensen, 2008; Guevara \& Solomon, 2009; Scott, 2008; Serin, 2005) and in the adult court system (Fahey, 2008; VanNostrand, 2007; Warren, 2007; Weibrecht, 2008).

Despite the growing popularity and promise of evidence-based programs and practices, the challenges associated with fully adopting this approach have been substantial and complex. As noted by Lipsey et al. (2010), practitioners are often ambivalent about the role science should play in guiding their interactions with clients and offenders. Moreover, implementation and sustainability problems are common, and evaluation efforts typically are met with resource issues and limited capacity to track outcomes. To deal with these issues, Lipsey and his colleagues (2010) recommend use of a "Comprehensive Strategy" for the prevention of juvenile delinquency and the production of intervention efforts guided by risk and needs assessment, case management plans, and graduated sanctions. They also provide a Standardized Program 
Evaluation Protocol (SPEP) for community agencies and organizations to use in comparing local juvenile justice programs to what has been found to be effective through evaluation research.

\section{Summary of the Problem and Theoretical Application}

It remains to be seen if evidence-based programs and practices will become the norm in the future field of juvenile justice. In order for this to occur, juvenile justice systems in most states will need to reduce their reliance on incarceration (particularly for minority youth), build effective evidence-based programs and practices in-line with the research literature, and ensure effective programs are targeted to appropriate offenders (Lipsey et al., 2010). Furthermore, meeting these challenges will require a clear view of expected juvenile justice outcomes, welldeveloped plans for achieving them, and effective use of management tools for implementation and evaluation. In other words, the future of juvenile justice appears to depend greatly on the systematic use and integration of strategic planning, evaluation, and evidence-based programs and practices. To date, relatively little is known about the extent to which this use and integration is occurring; the factors that predict the effective use of these recommended strategies; and the critical issues and needs confronting the juvenile justice system as it strives to improve the accountability and effectiveness of its operations.

It is known that resistance to performance measurement and monitoring in juvenile justice tends to share some common characteristics with resistance to evidence-based programs and practices (Lipsey et al., 2010; Mears, 2010; Mears \& Butts, 2008; Mears et al., 2008; Welsh \& Harris, 2008). Funding for research is nominal in most juvenile justice agencies, and practitioners may also fear that evidence-based programs and practices will siphon funding away from presumably effective, yet untested services. Many juvenile justice organizations may not 
have a cultural context and leadership that values strategic planning, continuous quality improvement, a desire to learn, or values related to excellence and client/offender success (Moynihan \& Landuyt, 2009; Moynihan \& Pandey, 2010). Perhaps most importantly, juvenile justice agencies and organizations may lack the analytical capacity, personnel, skills, and abilities necessary to effectively use and integrate strategic planning, evaluation, and evidencebased programs and practices (Davies \& Nutley, 2008; Emshoff, 2008; Tseng, 2010).

\section{Theoretical Framework}

In many fields involved with prevention and intervention efforts, there is an established gap between science and practice (Emshoff, 2008; Morrissey et al., 1997; Saul et al., 2008a, 2008b; Sherman et al., 2002). Effective prevention and intervention strategies typically have not been used on a wide enough scale to produce substantial population-level impacts, as strong links have not yet been established between discovering "what works" (i.e., evidence-based programs and practices) and widespread implementation and sustainability of these effective prevention and intervention strategies. In response to this situation, Wandersman and his colleagues (2008) have developed the Interactive Systems Framework (ISF) for Dissemination and Implementation. This theoretical framework facilitates an examination of the systems and processes involved in moving from the development and testing of innovations to the extensive use of effective strategies and techniques. In addition, the ISF can be applied to at least four major types of innovations: policies, programs, processes, and principles (Saul et al., 2008b).

The framework by Wandersman et al. (2008) centers on the infrastructure and systems needed to carry out the functions necessary for innovation dissemination and implementation to take place. The term "system" is used broadly in this context to describe a set of activities that may vary in the degree to which they are systematic or coherently organized. Moreover, the ISF 
also highlights the importance of capacity (both general and innovation-specific) within the various systems involved in the dissemination and implementation of innovations across settings. Finally, the model stresses the need for communication among different stakeholders in the system, such as funders, practitioners, trainers, and researchers.

The ISF itself consists of three collaborative systems: the Prevention Synthesis and Translation System, the Prevention Support System, and the Prevention Delivery System (Saul et al., 2008a; Wandersman et al., 2008). The function of the Prevention Synthesis and Translation System is conceptualized as distilling information about innovations and preparing them for implementation by end users. Theoretically, when information about innovations is accessible, user-friendly, and clearly demonstrates the utility of the innovations, the likelihood of successful dissemination and implementation of those innovations is increased (Backer, 2000; Clancy \& Cronin, 2005; Schoenwald \& Hoagwood, 2001). The Prevention Synthesis and Translation System works to distill information generated through research and to prepare it for dissemination and implementation in the field; the primary activities of this system are to synthesize existing research and translate it for use by practitioners. As the common products (e.g., journal articles, textbooks) that emerge from research processes may not be readily accessible or well understood by those who are delivering innovations in the field, practical information on innovations often must be synthesized and translated in order for practitioners to use it in everyday practice.

While synthesis and translation are important, studies have demonstrated that simply providing information about innovations is often not enough to produce change in programs and practices (Ringwalt et al., 2002; Rohrbach, D’Onofrio, Backer, \& Montgomery, 1996). In order to address the need for additional support to produce change, the Prevention Support System is 
presented as the second key component of the ISF (Wandersman et al., 2008). This system is conceptualized as carrying out innovation-specific support (or innovation-specific capacitybuilding) and general support (or general capacity-building). Innovation-specific capacitybuilding is assistance that is relevant to a specific innovation, and can include activities such as delivering information about an innovation before an organization decides if it wants to adopt it; providing training and on how to carry out an innovation before it is implemented; and providing technical assistance and coaching once an innovation is in use. In contrast, general capacitybuilding is intended to enhance the infrastructure, skills, and motivation of an organization, but it does not focus on a specific innovation. Examples of general capacity support include activities designed to assist with the production of organizational bylaws and policies, writing grants, forming collaborative partnerships, and developing leadership skills.

The third system in the ISF model is the Prevention Delivery System, which carries out the activities necessary to implement innovations (Wandersman et al., 2008). Implementation may take place at the organizational, community, state, or national level. The individuals, organizations, and communities that carry out prevention delivery activities may have varying levels of existing capacity (i.e., abilities and motivation) to implement innovations. The activities of the Prevention Delivery System include the application or use of general and innovationspecific capacities in the service of implementation. The use of general capacity consists of activities related to maintaining a functioning organization, such as hiring, training, and retaining skilled and competent staff; applying strong leadership skills; and communicating both internally and externally to the organization. The use of innovation-specific capacity, on the other hand, involves activities like gathering information and building knowledge about possible innovations 
to put in place, choosing which innovations to use, and taking steps to implement an innovation and sustain its use over time.

Wandersman et al. (2008) propose that each of the three systems of activities within the ISF is crucial for the successful dissemination and implementation of prevention activities in practice. In addition, they assert that the model can be applied to a wide variety of fields, including medicine, public health, human services, and education. Although Wandersman and his colleagues do not apply the model to criminal or juvenile justice, it is important to recognize that crime and delinquency prevention in America is sometimes misunderstood as signifying only "soft" approaches to preventing crime (as compared to "tougher" punishment-oriented practices). A complete definition of crime and delinquency prevention, however, encompasses any policy, program, or practice that causes a lower number of crimes to occur in the future than would have otherwise occurred without that policy, program, or practice (Farrington \& Welch, 2001; Sherman et al., 2002). Both peer mentoring programs and juvenile boot camps, for example, constitute efforts to prevent future crime.

Overall, the juvenile justice system, through its various policies, programs, and practices, seeks to reduce the amount of crime that would otherwise occur in the future without juvenile justice prevention and intervention efforts. Therefore, although not developed specifically for the field of juvenile justice, Wandersman et al.'s (2008) ISF model appears to be ideally suited for studying and guiding the use and integration of strategic planning, evaluation, and evidencebased programs and practices across the juvenile justice system. In particular, juvenile justice agencies and organizations may be lacking or vary greatly in their capacities to implement and sustain these recommended strategies, and a better understanding of how these capacities can be 
developed and expanded could have a substantial impact on juvenile justice system operations and effectiveness.

\section{The Importance of Capacity}

The concept of capacity commonly is used to describe the skills, motivations, knowledge, and attitudes that contribute to the accomplishment of actions or tasks (Flaspohler, Duffy, Wandersman, Stillman, \& Maras, 2008). Within Wandersman et al.'s (2008) ISF model, capacity can exist at the individual, organizational, and community levels, and it can be either innovationspecific or more general in nature. Innovation-specific capacity refers to specific motivations and skills, at the individual level, and human, technical, and fiscal conditions, at the organizational level, which are necessary to successfully implement and sustain a particular innovation. In contrast, general capacity refers to skills and characteristics, at the individual level, and overall functioning, at the organizational and community levels, which are associated with the ability to implement and sustain any type of innovation. In an era of increasing demands for accountability from policy-makers, funding providers, and the general public, capacity has emerged as a key concept, as quality implementation and sustainability of innovations have become common expectations in virtually all prevention and intervention efforts (Durlak \& DuPre, 2008; Livet, Courser, \& Wandersman, 2008).

Individual capacities of members of organizations and communities play an important role in their ability to implement and sustain an innovation. As discussed by Flaspohler and his colleagues (2008) and Durlak and DuPre (2008), a number of empirical studies have identified various individual-level elements of importance. Concerning individual innovation-specific capacities, understanding of problems and innovations, perceived skills and abilities to 
implement and sustain an innovation, and innovation buy-in (e.g., attitudes, commitment, and anticipated outcomes associated with an innovation) all have been found to be associated with the adoption of evidence-based programs and practices (Hunter et al., 2009; Livet \& Wandersman, 2005; Schoenwald \& Hoagwood, 2001). In terms of individual general capacities, educational level, flexibility, openness to new knowledge, and values on learning and growth have been found to influence the dissemination and implementation process (Greenhalgh, Robert, Macfarlane, Bate, \& Kyriakidou, 2004).

Organizational capacities include the characteristics that an organization needs in order to function and successfully carry out activities and innovations (Durlak \& DuPre, 2008; Flaspohler et al., 2008). At the organizational level, successful adoption, implementation, and sustainability of a specific innovation typically entails formal procedures for decision-making and evaluation. Organizational innovation-specific capacities found through research to be important include innovation fit with organizational goals, values, practices, needs, and abilities; support from the organization, in terms of commitment, climate, and resources; buy-in from the organization, as indicated by innovation supporters, connected champions, and staff agreement on innovation values, selection, and sustainability; access to training and technical assistance, as well as ongoing consultation, coaching, and supervision; and the presence of evaluation systems and skills to monitor and assess the effectiveness and relative advantage of an innovation (Elliot \& Mihalic, 2004; Greenhalgh et al., 2004; Hunter et al., 2009; Livet et al., 2008; Livet \& Wandersman, 2005; Schoenwald \& Hoagwood, 2001).

Organizational general capacities also have been found to be important in the dissemination and implementation process (Durlak \& DuPre, 2008; Flaspohler et al., 2008). Key factors identified by researchers include leadership development and strength, along with clear 
and articulated vision and mission statements; an organizational structure and management style that is flexible, decentralized, collaborative, strategic, and stable; an organizational climate that is cohesive, receptive to change, and open to experimentation and risk-taking; the availability of adequate resources, including facilities, equipment, funding, competent staff, and data management systems; and the presence of external relationships, exhibited through community participation and support and inter-agency collaborations and partnerships (Elliot \& Mihalic, 2004; Fredericksen \& London, 2000; Greenhalgh et al., 2004; Livet et al., 2008; Livet \& Wandersman, 2005).

Finally, organizational capacity tends to be linked to the capacity of the community in which an organization is located (Durlak \& DuPre, 2008; Flaspohler et al., 2008). Community capacity emphasizes the importance of connections within the community, both at the individual level (e.g., social connections, social support) and at the organizational level (e.g., networking between organizations, formal coalitions). Again, research has uncovered a number of factors that influence the implementation of community innovations, including leadership; participation and opportunities for participation by community members; resource mobilization and accessibility; social connections and inter-organizational networks; connections with outside communities and institutions; community trust and climate; community norms, values, and attitudes; community commitment and power; and community knowledge, skills, and understanding of problems and innovations (Edwards, Jumper-Thurman, Plested, Oetting, \& Swanson, 2000; Eng \& Parker, 1994; Goodman et al., 1998; Labonte \& Laverack, 2001; Zimmerman, 2000).

Theoretically, under Wandersman et al.'s (2008) ISF model, capacity-building takes place through the activities of the Prevention Synthesis and Translation System and the 
Prevention Support System, and individuals, organizations, and communities with greater capacities will be better able to support and maintain a Prevention Delivery System that implements and sustains effective innovations. Although studies from various fields support the importance of capacity in dissemination and implementation efforts, little research of this type has been conducted in the field of juvenile justice, and further research also is needed to address specific research questions and test hypotheses derived from ISF theory (Durlak \& DuPre, 2008; Flaspohler et al., 2008; Livet et al., 2008; Wandersman et al., 2008).

Discussion and Proposed Research Agenda

Within the modern "accountability movement" in juvenile justice, the use of performance measurement, monitoring, and evidence-based programs and practices have emerged as key recommended strategies for improving juvenile court operations and outcomes (Bazemore, 2006; Harp et al., 2006; Lipsey et al., 2010; Mears \& Butts, 2008; Sherman et al., 2002; Thomas, 2006, 2008). However, many juvenile justice agencies and organizations have difficulty producing empirical evidence about their performance, likely due to poor planning and/or poor implementation and evaluation of their programs and services (Mears, 2010; Mears \& Butts, 2008; Welsh \& Harris, 2008). In an era of declining resources and economic challenges, juvenile courts and other youth-serving agencies can expect that requirements for providing and measuring strategic goals and objectives and utilizing effective programs and practices will continue (Moynihan \& Pandey, 2010). To date, little research in juvenile justice has been conducted on the use and integration of recommended contemporary strategies, and little is known about the factors that predict their implementation and the critical issues and needs confronting the juvenile justice system as it strives to improve its accountability and effectiveness. 
In order to generate new ideas for bridging science and practice, the Interactive Systems Framework (ISF) for Dissemination and Implementation has been offered by Wandersman et al. (2008) as a model for guiding research and practice across various fields involved with prevention activities and innovations. Although ISF is promising as a theoretical model, various challenges exist for dissemination and/or implementation within each of the three major systems in the framework (i.e., Prevention Synthesis and Translation, Prevention Support, and Prevention Delivery Systems), and these challenges also suggest a number of important areas in need of further research (Emshoff, 2008; Saul et al., 2008a).

To begin, the Prevention Synthesis and Translation System (PSTS) works to distill information generated through research, and then prepares it for dissemination and implementation in the field. The primary activities of this system are to synthesize existing research and translate it for use by practitioners (Wandersman et al., 2008). Key challenges in the PSTS include a general lack of support for researchers engaged in synthesis and translation activities, and a lack of clear guidance for practitioners on how to access research syntheses (Emshoff, 2008; Saul et al., 2008a). Perhaps most importantly, knowledge is limited about whether and how prevention delivery practitioners understand and use available research on innovations, and how useful this information is to them (Lesesne et al., 2008). Juvenile justice professionals, for example, may be unsure of which sources of synthesized information are credible, and among those that are credible, which ones contain content that is most relevant to their work. It is also likely that the recipients of this information will differ in their perceptions and abilities to use the information and resources effectively. These issues suggest a number of questions that can be investigated in future research: 
- Who are the main juvenile justice practitioners who consume research, and are they utilizing translation and synthesis materials?

- How do juvenile justice professionals access the latest research and translation and synthesis materials?

- What is the best format and content for this information and literature?

- How can researchers more effectively communicate with practitioners and disseminate resources to ensure that juvenile justice audiences learn about important research findings?

- What additional materials do juvenile justice practitioners need to act on the available research evidence?

- What can be done through translation and synthesis to increase the perceived advantages of performance measurement, monitoring, and use of evidence-based programs and practices?

Next, the Prevention Support System (PSS) has a critical role in bridging the gap between research and practice (Wandersman et al., 2008). The primary functions of this system include innovation-specific capacity-building (assistance that is related to using a specific innovation) and general capacity-building (assistance that enhances the infrastructure, skills, and motivations of an organization, but does not focus on a specific innovation). Assistance can be provided in a number of ways, such as through training, technical assistance, and coaching. Key challenges in the PSS include an overall lack of access to existing prevention support, and a lack of systematic and high-quality prevention support (Emshoff, 2008; Saul et al., 2008a). As resources become limited, it is increasingly important to determine which types of practitioners should be targeted for prevention support and capacity-building (Hunter et al., 2009; Lesesne et al., 2008). Limited 
research suggests, for example, that practitioners with the least capacity are less likely than those with more capacity to seek out technical assistance, even when it is available (Saul et al., 2008a). Furthermore, popular mechanisms for providing prevention support tend to be one-time, didactic, continuing education courses and training workshops, despite research evidence suggesting these approaches are unlikely to change practitioner behavior (Saul et al., 2008a). In sum, the need for more information on how to effectively build capacity also suggests a number of questions for future juvenile justice studies to investigate:

- Are the supports currently provided through training, technical assistance, and coaching meeting the needs of juvenile justice professionals?

- What types (i.e., style and content) of capacity-building assistance are juvenile justice professionals most likely to receive?

- Do juvenile justice professionals have access to both innovation-specific capacitybuilding opportunities and general capacity-building opportunities?

- Are juvenile justice professionals engaged in opportunities to build capacity at the individual, organizational, and community levels?

- Are there associations between the assistance and supports being received and the types and amounts of capacity reported by juvenile justice professionals?

- Are there associations between the assistance and supports being received, types and amounts of capacity reported, and the use of performance measurement, monitoring, and evidence-based programs and practices?

Finally, the Prevention Delivery System (PDS) carries out the activities necessary to implement and sustain innovations in practice, and these activities can exist at the organizational, community, state, or national levels (Wandersman et al., 2008). The activities of the PDS involve 
the application or use of general and innovation-specific capacities during and following the implementation of innovations. The use of general capacity consists of activities related to maintaining an overall functioning organization, while the use of innovation-specific capacity focuses on building knowledge about possible innovations to put in place and taking steps to implement an innovation and sustain its use over time. As with the other two systems, several challenges currently exist within the PDS (Emshoff, 2008; Saul et al., 2008a). These challenges include a lack of organizational infrastructure (e.g., networking and collaboration, financial and human resources, leadership and communication); a need to better understand the entire implementation process (e.g., planning, initial implementation, evaluation, maintenance, and sustainability); a lack of in-depth information regarding adaptation and transportability of innovations (particularly when the innovation is a well-defined program); and a need for increased strategic planning, implementation, and evaluation at the local level (while recognizing a general lack of knowledge, skills, and resources in these areas). Once again, these issues and needs point toward several questions for juvenile justice research to investigate:

- What are the key limitations of organizational infrastructure experienced by juvenile justice professionals?

- How well do juvenile justice professionals understand the various stages of implementation, and are they being guided by research-based knowledge and evidence in implementing programs and other innovations?

- To what degree does adaptation of juvenile justice programs and other innovations take place, and how does this adaptation take place (e.g., is it being guided by research-based knowledge and evidence)? 
- To what degree are strategic planning, evaluation, and use of evidence-based programs and practices taking place at the local level of juvenile justice?

- What are the key individual, organizational, and community factors that predict the use and integration of strategic planning, evaluation, and evidence-based programs and practices at the local level of juvenile justice?

- How well does the Interactive Systems Framework (ISF) for Dissemination and Implementation explain the use and integration of strategic planning, evaluation, and evidence-based programs and practices at the local level of juvenile justice?

\section{Conclusion}

This article sought to examine the key aspects of the modern accountability movement in juvenile justice and discuss a recently proposed theory that may be useful in better understanding how juvenile justice system improvement efforts can be better implemented, evaluated, and sustained. Performance measurement and monitoring, along with the use of evidence-based programs and practices, have become highly advocated yet under-utilized approaches to enhancing the effectiveness of juvenile justice system operations. Recently proposed theory by Wandersman and his colleagues (2008) appears to hold promise for advancing the dissemination and implementation of a wide variety of innovations, including those recommended for adoption in the juvenile justice system. Further theoretical application and empirical research should be useful in identifying the strengths and limitations of the ISF model, bridging the gap between science and practice, and promoting more effective prevention and intervention efforts in the field. 


\section{References}

Aarons, G. A., \& Sawitzky, A. C. (2006). Organizational culture and climate and mental health provider attitudes toward evidence-based practice. Psychological Services, 3(1), 6172.

Backer, T. E. (2000). The failure of success: Challenges of disseminating effective substance abuse prevention programs. Journal of Community Psychology, 28(3), 363-373.

Bazemore, G. (2006). Measuring what really matters in juvenile justice. Alexandria, VA: American Prosecutors Research Institute.

Carter, M. M., Gibel, S., Giguere, R., \& Stroker, R. (2007). Increasing public safety through successful offender reentry: Evidence-based and emerging practices in corrections. Silver Spring, MD: Center for Effective Public Policy.

Christensen, G. E. (2008). Our system of corrections: Do jails play a role in improving offender outcomes? Washington, DC: National Institute of Corrections

Clancy, C. M., \& Cronin, K. (2005). Evidence-based decision making: Global evidence, local decisions. Health Affairs, 24(1), 151-162.

Cullen, F. T. (2006). It's time to reaffirm rehabilitation. Criminology and Public Policy, 5, 665672.

Davies, H. T. O., \& Nutley, S. M. (2008). Learning more about how research-based knowledge gets used: Guidance in the development of new empirical research. New York: William T. Grant Foundation.

Durlak, J. A., \& DuPre, E. P. (2008). Implementation matters: A review of research on the influence of implementation on program outcomes and the factors affecting implementation. American Journal of Community Psychology, 41, 327-350. 
Edwards, R. W., Jumper-Thurman, P., Plested, B. A., Oetting, E. R., \& Swanson, L. (2000). Community readiness: Research to practice. Journal of Community Psychology, 28(3), 291-307.

Elliot, D. S., \& Mihalic, S. (2004). Issues in disseminating and replicating effective prevention programs. Prevention Science, 5(1), 47-52.

Emshoff, J. G. (2008). Researchers, practitioners, and funders: Using the framework to get us on the same page. American Journal of Community Psychology, 41, 393-403.

Eng, E., \& Parker, E. (1994). Measuring community competence in the Mississippi Delta: The interface between program evaluation and empowerment. Health Education Quarterly, 21(2), 199-220.

Fahey, J. A. (2008). Using research to promote public safety: A prosecutor's primer on evidence-based practice. Washington, DC: National Institute of Corrections.

Farrington, D. P., \& Welch, B. C. (2001). What works in preventing crime? Systematic reviews of experimental and quasi-experimental research. The Annals of the American Academy of Political and Social Science. Thousand Oaks, CA: Sage Publications.

Flaherty-Zonis, C. (2007). Building culture strategically: A team approach for corrections. Washington, DC: National Institute of Corrections

Flaspohler, P., Duffy, J., Wandersman, A., Stillman, L., \& Maras, J. A. (2008). Unpacking prevention capacity: An intersection of research-to-practice models and communitycentered models. American Journal of Community Psychology, 41, 182-196.

Fredericksen, P., \& London, R. (2000). Disconnect in the hollow state: The pivotal role of organizational capacity in community-based developmental organizations. Public Administration Review, 60, 230-239. 
Goodman, R., Speers, M., McLeroy, K., Fawcett, S., Kegler, M., Parker, E. (1998). Identifying and defining the dimensions of community capacity to provide a basis for measurement. Health Education Behavior, 25, 258-278.

Greenhalgh, T., Robert, G., Macfarlane, F., Bate, P., \& Kyriakidou, O., (2004). Diffusion of innovations in service organizations: Systematic review and recommendations. Millbank Quarterly, 82, 581-629.

Guevara, M., \& Solomon, E. (2009). Implementing evidence-based policy and practice in community corrections ( $2^{\text {nd }}$ ed.). Washington, DC: National Institute of Corrections.

Harp, C., Bell, D., Bazemore, G., \& Thomas, D. (2006). Guide to developing and implementing performance measures for the juvenile justice system. Alexandria, VA: American Prosecutors Research Institute.

Howell, J. C. (1997). Juvenile justice and youth violence. Thousand Oaks, CA: Sage.

Howell, J. C. (2003). Preventing \& reducing juvenile delinquency: A comprehensive framework. Thousand Oaks, CA: Sage.

Hunter, S. B., Paddock, S. M., Ebener, P., Burkhart, A. K., \& Chinman, M. (2009). Promoting evidence-based practices: The adoption of a prevention support system in community settings. Journal of Community Psychology, 37(5), 579-593.

Krisberg, B. (2005). Juvenile justice: Redeeming our children. Thousand Oaks, CA: Sage.

Kyler, S. J., Bumbarger, B. K., \& Greenberg, M. T. (2005). Technical assistance fact sheet: Evidence-based programs. University Park, PA: Penn State Prevention Research Center. Labonte, R., \& Laverack, G. (2001). Capacity building in health promotion, Part I: For whom? And for what purpose? Critical Public Health, 11, 111-127. 
Lesesne, C. A., Lewis, K. M., White, C. P., Green, D. C., Duffy, J. L., \& Wandersman, A. (2008). Promoting science-based approaches to teen pregnancy prevention: Proactively engaging in three systems of the interactive systems framework. American Journal of Community Psychology, 41, 379-392.

Lipsey, M. W., Howell, J. C., Kelly, M. R., Chapman, G., \& Carver, D. (2010). Improving the effectiveness of juvenile justice programs: A new perspective on evidence-based practice. Washington, DC: Center for Juvenile Justice Reform.

Livet, M., Courser, M., \& Wandersman, A. (2008). The prevention delivery system: Organizational context and use of comprehensive programming frameworks. American Journal of Community Psychology, 41, 361-378.

Livet, M., \& Wandersman, A. (2005). Organizational functioning: Facilitating effective interventions and increasing the odds of programming success. In D. Fetterman \& A. Wandersman (Eds.), Empowerment evaluation principles in practice. New York: Guilford Publications.

Mears, D. P. (2010). American criminal justice policy: An evaluation approach to increasing accountability and effectiveness. New York: Cambridge University Press.

Mears, D. P., \& Butts, J. A. (2008). Using performance monitoring to improve the accountability, operations, and effectiveness of juvenile justice. Criminal Justice Policy Review, 19(3), 264-284.

Mears, D. P., Shollenberger, T. L., Willison, J. B., Owens, C. E., \& Butts, J. A. (2010). Practitioner views of priorities, policies, and practices in juvenile justice. Crime \& Delinquency, 56(4), 535-563. 
Morrissey, E., Wandersman, A., Seybolt, D., Nation, M., Crusto, C., \& Davino, K. (1997).

Toward a framework for bridging the gap between science and practice in prevention: A focus on evaluator and practitioner perspectives. Evaluation and Program Planning, 20, 367-377.

Moynihan, D. P., \& Landuyt, N. (2009). How do public organizations learn? Bridging cultural and structural perspectives. Public Administration Review, 69(6), 1097-1105.

Moynihan, D. P., \& Pandey, S. K. (2010). The big question for performance management: Why do managers use performance information? Journal of Public Administration Research and Theory, 20, 849-866.

Nelson, S. R., Leffler, J. C., \& Hansen, B. A. (2009). Toward a research agenda for understanding and improving the use of research evidence. Portland, OR: Northwest Regional Educational Laboratory.

Ringwalt, C., Ennet, S., Vincus, A., Thorne, J., Rohrbach, L. A., \& Simons-Rudolph, A. (2002). The prevalence of effective substance use prevention curricula in U.S. middle schools. Prevention Science, 3(4), 257-265.

Rohrbach, L. A., D’Onofrio, C., Backer, T. E., \& Montgomery, S. (1996). Diffusion of schoolbased substance abuse prevention programs. American Behavioral Scientist, 39(7), 919934.

Rossi, P. H., Lipsey, M. W., \& Freeman, H. (2004). Evaluation: A systematic approach (7 $7^{\text {th }}$ ed.). Thousand Oaks, CA: Sage. 
Saul, J., Duffy, J., Noonan, R., Lubell, K., Wandersman, A., Flaspohler, P., Stillman, L., Blachman, M., \& Dunville, R. (2008a). Bridging science and practice in violence prevention: Addressing ten key challenges. American Journal of Community Psychology, 41, 197-205.

Saul, J., Wandersman, A., Flaspohler, P., Duffy, J., Lubell, K., Noonan, R. (2008b). Research and action for bridging science and practice in prevention. American Journal of Community Psychology, 41, 165-170.

Schoenwald, S. K., \& Hoagwood, K. (2001). Effectiveness, transportability, and dissemination of interventions: What matters when? Psychiatric Services, 52(9), 1190-1197.

Scott, W. (2008). Effective clinical practices in treating clients in the criminal justice system. Washington, DC: National Institute of Corrections.

Serin, R. C. (2005). Evidence-based practice: Principles for enhancing correctional results in prisons. Washington, DC: National Institute of Corrections.

Sherman, L. W., Farrington, D. P., Welsh, B. C., \& MacKenzie, D. L. (2002). Evidence-based crime prevention. New York: Routledge.

Snyder, H. N., \& Sickmund, M. (1995). Juvenile offenders and victims: A national report. Washington, DC: Office of Juvenile Justice and Delinquency Prevention.

Snyder, H. N., \& Sickmund, M. (1999). Juvenile offenders and victims: 1999 National Report. Washington, DC: Office of Juvenile Justice and Delinquency Prevention.

Stroker, R. (2010). Establishing a rational planning process. Silver Spring, MD: Center for Effective Public Policy.

Thomas, D. (2005). Measuring juvenile justice system performance: More jurisdictions taking the next and necessary step. Youth and Family Court Today, Fall 2005, 10-11. 
Thomas, D. (2006). "How does the juvenile justice system measure up? Applying performance measures in five jurisdictions." Technical Assistance to the Juvenile Court Bulletin. Pittsburgh, PA: National Center for Juvenile Justice.

Thomas, D. (2008). "Drilling down: Exploring performance measures to improve juvenile justice.” Technical Assistance to the Juvenile Court Bulletin. Pittsburgh, PA: National Center for Juvenile Justice.

Torbet, P., Gable, R., Hurst, H. I., Montgomery, I., Szymanski, L., \& Thomas, D. (1996). State responses to serious and violent juvenile crime. Washington, DC: Office of Juvenile Justice and Delinquency Prevention.

Torbet, P., \& Szymanski, L. (1998). State legislative responses to violent juvenile crime: 19961997 update. Washington, DC: Office of Juvenile Justice and Delinquency Prevention.

Tseng, V. (2010). "Learning about the use of research to inform evidence-based policy and practice: Early lessons and future directions." William T. Grant Foundation 2009 Annual Report. New York: William T. Grant Foundation.

VanNostrand, M. (2007). Legal and evidence-based practices: Applications of legal principles, laws, and research to the field of pre-trial services. Washington, DC: National Institute of Corrections.

Wandersman, A., Duffy, J., Flaspohler, P., Noonan, R., Lubell, K., Stillman, L., Blachman, M., Dunville, R., \& Saul, J. (2008). Bridging the gap between prevention research and practice: The interactive systems framework for dissemination and implementation. American Journal of Community Psychology, 41, 171-181.

Warren, R. K. (2007). Evidence-based practice to reduce recidivism: Implications for state judiciaries. Washington, DC: National Institute of Corrections. 
Weibrecht, K. A. (2008). Evidence-based practices and criminal defense: Opportunities, challenges, and pre-trial considerations. Washington, DC: National Institute of Corrections.

Welsh, W. N., \& Harris, P. W. (2008). Criminal justice policy \& planning ( ${ }^{\text {rd }}$ ed.). Newark, NJ: LexisNexis/Anderson Publishing.

Zimmerman, M. A. (2000). Empowerment theory: Psychological, organizational, and community levels of analysis. In J. Rappaport \& E. Seidman (Eds.), Handbook of community psychology (pp. 43-63). Dordrecht, Netherlands: Kluwer Academic Publishers.

Zimring, F. E. (2005). American juvenile justice. New York: Oxford University Press. 